\title{
MORBIDADE HOSPITALAR POR CONTATO COM ANIMAIS E PLANTAS VENENOSAS NO ESTADO DO ACRE
}

\author{
Leila Keury Costa Lima ${ }^{1}$; Frankllin Ramon da Silva ${ }^{1}$; Eder Ferreira de Arruda ${ }^{2}$ \\ ${ }^{1}$ Bacharel em Enfermagem, Centro Universitário UNINORTE, Rio Branco, Acre. \\ ${ }^{2}$ Docente, Centro Universitário UNINORTE, Rio Branco, Acre.
}

E-mail: leilakeury.lima@gmail.com

DOI: $10.47094 /$ ICONNACT.2020/15-18

\section{RESUMO}

Introdução: A intoxicação exógena por contato com animais e plantas venenosas constitui uma importante causa de morbidade hospitalar. Objetivo: Descrever o panorama das internações causadas por contato com animais e plantas venenosas no Estado do Acre no ano de 2019. Metodologia: Trata-se de um estudo observacional descritivo, de corte transversal, com abordagem quantitativa, com dados do Sistema de Informações Hospitalares disponíveis no site do DATASUS sobre as internações causadas por contato com animais e plantas venenosas. Resultados: No Acre, no ano de 2019, foram registrados 111 casos de internações por contato com animais e plantas venenosas, sendo que a maioria ocorreu com indivíduos na faixa etária de 20 a 39 anos $(35,1 \%)$ e do sexo masculino (73,9\%). Considerações finais: A morbidade hospitalar por contato com animais e plantas venenosas pode ser considerada como um problema de saúde pública em virtude do percentual de indivíduos acometidos no Estado do Acre.

Palavras-chave: Hospitalização; Epidemiologia; Toxicologia.

\section{INTRODUÇÃO}

As intoxicações por causas exógenas consistem em um conjunto de sinais e sintomas tóxicos, causados por alguma substância não produzida pelo organismo provocando alterações que necessitam de atendimento de urgência e internações são bastante frequentes nos serviços de saúde do mundo inteiro (RIBEIRO et al., 2020).

No Brasil, as intoxicações exógenas representam um grande problema de saúde pública, pois de acordo com Sistema de Informação de Agravos de Notificação (SINAN), no período de 2007 a 2017, foram notificados 470.913 casos (BRASIL, 2020).

Dentre as principais causas exógenas, se destacam os acidentes por contato com animais e 
plantas venenosas, pois se constituem uma importante causa de internações hospitalares, sendo que no Brasil os acidentes envolvendo animais, no ano de 2011, provocaram 15.672 internações hospitalares e 328 óbitos (CARMO et al., 2016). Já em 2017, foram notificados 33 casos pela mesma causa em trabalhadores do estado do Acre (BRASIL, 2019). Por sua vez, o número de intoxicações ocasionadas por plantas, no ano de 2012, foi de 1026 casos, o que correspondente a 1,2\% dos casos de intoxicação humana (SINITOX, 2012).

A exposição aos animais peçonhentos envolve, principalmente, os trabalhadores rurais, por sua proximidade com o ambiente natural dos animais. Já a intoxicação por plantas é menos frequente entre adultos, mas ocorrem, sobretudo pelo mal uso de plantas medicinais, chás, fitoterapia e, também, plantas que causam alucinações e que provocam abortos (CARMO et al., 2016; SÃO PAULO, 2017).

Diante ao exposto, o objetivo do presente foi descrever o panorama das internações causadas por contato com animais e plantas venenosas no Estado do Acre no ano de 2019.

\section{METODOLOGIA}

Foi realizado um estudo observacional descritivo, de corte transversal, com abordagem quantitativa sobre o panorama das internações causadas por contato com animais e plantas venenosas no estado do Acre em todas as faixas etárias.

Os dados foram obtidos durante o mês de novembro de 2020, a partir do Sistema de Informações Hospitalares (SIH) disponíveis no site do Departamento de Informática do Sistema Único de Saúde (DATASUS).

Os dados foram analisados de acordo com a frequência de notificação, taxa de morbidade hospitalar, faixa etária e sexo por meio do programa Microsoft ${ }^{\circledR}$ Office Excel 2016 no qual foram calculadas as frequências absolutas e relativas das variáveis.

\section{RESULTADOS E DISCUSSÃO}

No estado do Acre, no ano de 2019, foram registrados 111 casos de internações por contato com animais e plantas venenosas. Em contraste com este achado, uma análise feita por Lopes et al. (2017) identificou no Acre, entre os anos de 2012 à 2015, o total de 3.581 notificações de acidentes por animais peçonhentos, com média anual de aproximadamente 895 casos. Por sua vez, em Tocantins ocorreram 4.937 registros de acidentes com animais peçonhentos no mesmo ano (GONÇALVES et al., 2020).

No estado, 28,8\% das notificações ocorreram no município de Cruzeiro do Sul e a maior taxa de morbidade hospitalar foi identificada na cidade de Sena Madureira, com 5,02 hospitalizações a 
cada 10.000 habitantes (5,02/10.000hab). Resultados superiores foram encontrados por Coelho et al. (2017) em Palmas (TO) no qual, em números absolutos, verificaram 14 óbitos por contato com animais e plantas venenosas, entre os anos de 2008 a 2015 e por Batista et al. (2018) no estado de Sergipe onde no ano de 2017 registrou-se apenas oito internações em caráter de urgência pelo mesma causa.

A maioria dos casos ocorreu com indivíduos na faixa etária de 20 a 39 anos $(35,1 \%)$ e do sexo masculino (73,9\%). Semelhantemente, em estudo realizado no estado do Tocantins, que analisou os acidentes com animais peçonhentos entre os anos de 2009 a 2019, a faixa etária com maior número de casos foi de 20 a 39 com $35,81 \%$ das notificações e o sexo masculino registrou $60,52 \%$ dos casos (GONÇALVES et al., 2020). De igual modo, Lopes et al. (2017) ao analisarem o perfil epidemiológico dos acidentes por animais peçonhentos na região norte também identificaram uma maior ocorrência de casos, no grupo etário de 20 a 39 anos e um declínio progressivo com o avançar da idade, bem como o maior acometimento do sexo masculino.

\section{CONSIDERAÇÕES FINAIS}

Os resultados demostraram que a morbidade hospitalar por contato com animais e plantas venenosas pode ser considerada como um problema de saúde pública em virtude do percentual de indivíduos acometidos no Estado do Acre. Portanto, se faz necessário promover a capacitação dos profissionais de saúde no atendimento das vítimas e também na adoção de estratégias e medidas de promoção em saúde voltadas para a disseminação de informações preventivas a fim de reduzir o número de novos casos.

\section{PRINCIPAIS REFERÊNCIAS}

BATISTA, J. F. C. et al. Atendimento nas urgências: causas externas como fator de internação em Sergipe, 2017. Congresso Nacional de Enfermagem-CONENF, v.1, n.1, p.1-5, 2018.

BRASIL. Boletim Epidemiológico. v.50, n.11, 2019. Disponível em: https://portalarquivos2.saude. gov.br/images/pdf/2019/marco/29/2018-059.pdf. Acesso em: 28 nov. 2020.

BRASIL. Sistema de Informação de Agravos de Notificação (SINAN). 2020. Disponível em: https://portalsinan.saude.gov.br/intoxicacao-exogena. Acesso em: 30 nov. 2020.

CARMO, E. A. et al. Internações hospitalares por causas externas envolvendo contato com animais em um hospital geral do interior da Bahia, 2009-2011. Epidemiologia e Serviços de Saúde [online], v. 25, n.1, p. 105-1, 2016.

COELHO, A. P. S. et al. Levantamento das internações e óbitos por causas ambientais no município 
de Palmas/Tocantins de 2008 a 2015. Revista de Patologia do Tocantins, v. 4, n.4, p.7-12, 2017.

GONÇALVES, C. W. B. et al. Acidentes com animais peçonhentos em um estado do Norte do Brasil. Scientia Generalis, v.1, n.3, p.37-43, 2020.

LOPES, A. B. et al. Perfil epidemiológico dos acidentes por animais peçonhentos na região norte entre os anos de 2012 e 2015. Revista de Patologia do Tocantins, v. 4, n.2, p.36-40, 2017.

RIBEIRO, A. T. et al. O perfil das intoxicações medicamentosas no Brasil. Brazilian Journal of Development, v.6, n.3, p.9632-9634, 2020.

SÃO PAULO. Manual de Toxicologia Clínica: Orientações para assistência e vigilância das intoxicações agudas. São Paulo: Secretaria Municipal da Saúde, 2017. Disponível em: http://www. cvs.saude.sp.gov.br/up/MANUAL\%20DE\%20TOXICOLOGIA\%20CL\%C3\%8DNICA\%20-\%20 COVISA\%202017.pdf. Acesso em: 29 nov. 2020. 